Z. klin. Chem. u. klin. Biochem.

7. Jg., S. 53-55, Januar 1969

\title{
Isolierung von Antikörpern vom IgA-Typus
}

\author{
Von K. SChUMacher \\ Aus der Medizinischen Universitätsklinik Köln-Lindenthal (Direktor: Prof. Dr. R. Gross)
}

Eingegangen am 25. September 1968)

Es wird ein Verfahren zur Isolierung von $\gamma \mathrm{A}$-Globulin beschrieben, das in wenigen Trennschritten zu einem immunologisch reinen Präparat führt. Nach einer Zinksulfatfällung von vorpräzipitiertem Serum mit anschließender Ammoniumsulfatfällung wurde eine Molekularsiebung an Sephadex G-200 durchgeführt, die zur Isolierung einer $13 \mathrm{~S}$ - und einer 7 S-Komponente von $\gamma \mathrm{A}-\mathrm{Globulin}$ führte. Immunelektrophoretisch waren beide Komponenten einheitlich. Das Verfahren wurde zur Isolierung von Antikörpern gegen partikuläre Leberzellantigene verwendet. Die Antikörperaktivität der $\gamma$ A-Globuline wurde durch das Trennverfahrẹn nicht beeinträchtigt.

\section{Isolation of IgA-tJ'pe antibodies}

A method for the isolation of $\gamma \mathrm{A}$-globulin is described. Only a few separation steps are needed to obtain an immunologically pure preparation. After precipitation of serum with zinc sulphate and ammonium sulphate, the solubilised precipitate was separated by molecular sieving on Sephadex G-200. The eluate contained a $13 \mathrm{~S}$ and a $7 \mathrm{~S}$ component of $\gamma \mathrm{A}$-globulin. In immunoelectrophoresis the two components were identical. The method was used for the isolation of antibodies against antigens from liver cells. The activity of the antibody of $\gamma \mathrm{A}$-globulin type was not diminished by the separation procedure.

Während die präparative Darstellung von $\gamma$ G-Globulinen experimentell keine Schwierigkeiten bereitet (1), stehen für die Isolierung von $\gamma \mathrm{A}$ - und $\gamma \mathrm{M}$-Globulinen bisher einfache Verfahren nicht zur Verfügung $(2,3,4$, 5). Das von Vaerman und Mitarbeitern (2) angegebene Verfahren zur Isolierung von $\gamma \mathrm{A}$-Globulinen wurde von HEIDE und HAUPT (3) leicht modifiziert; beide Methoden enthalten aber noch eine Reihe von Trennschritten. Zur Isolierung von Antikörpern vom IgA-Typus bei Patienten mit biliärer Lebercirrhose versuchten wir durch weitere Modifikation dieser Methode ein Verfahren zu finden, das gleichzeitig einfach und schonend ist und nicht zu einer Beeinträchtigung der Antikörper-Aktivität führt.

\section{Methodik \\ Fällungsreaktion}

Humanserum wurde zunächst, entsprechend dem Verfahren von HeIDE und Haupt (3) 24 Stdn. gegen Wasser, pH 5,5 dialysiert. Nach Abzentrifugieren der nicht-wasserlöslichen Proteine wurde der Ưberstand auf einen Proteingehalt von $30 \mathrm{mg} / \mathrm{ml}$ eingestellt. Der $\mathrm{pH}$-Wert wurde mit festem $\mathrm{Na}_{2} \mathrm{HPO}_{4}$ auf 6,0 korrigiert. Anschließend wurde Zinksulfat bis zu einer Endkonzentration von 0,05ir zugegeben. Nach Einstellen des pH-Wertes auf 6,8 wurde nach $60 \mathrm{Min}$. der Niederschlag abzentrifugiert. Der Uberstand wurde mit Glycin bis zu einer Konzentration von $2 \%$ versetzt. Anschließend wurde Ammoniumsulfat bis zu einer Endkonzentration von 2,0 M unter ständigem Rühren zugegeben. Der abzentrifugierte Niederschlag wurde in Tris- $\mathrm{HCl}$ Puffer aufgenommen und gegen häufig gewechselten Säulenpuffer dialysiert bis zur völligen Lösung der Proteine.

\section{Gelfiltration}

Die weitere Fraktionierung der Proteine erfolgte durch Molekularsiebung an Sephadex G-200 (Pharmacia, Uppsala) an einer Gelpackung von $950 \times 28 \mathrm{~mm}$. Als Säulenpuffer wurde ein $0,1 \mathrm{M}$ Tris- $\mathrm{HCl}$ Puffer, pH $8,0+0,1 \mathrm{M} \mathrm{NaCl}$, verwendet (6). Die Auftragungsmenge betrug $360-450 \mathrm{mg}$ Protein. Eluiert wurde mit $10 \mathrm{~m} l / \mathrm{Std}$.

\section{Immunelektrophorese}

Es wurde die Mikromethode nach SCHEIDEGGER (7) verwendet. Die Ausführung erfolgte in 1,5proz. Agar (Reinagar, Behring-
Werke, Marburg) in 0,01M Na-Barbiturat Puffer $\mathrm{pH} 8,6 \mathrm{mit}$ Zusatz von Cialit 1:10000. Als Elektrodenpuffer wurde ein $0,1 \mathrm{M}$ Na-Barbituratpuffer $\mathrm{pH}$ 8,6 verwendet. Die Elektrophorese wurde mit $12 \mathrm{~mA}$ pro Plattenrahmen (LKB-Produkter, Stockholm) und etwa $250 \mathrm{~V}$ durchgeführt. Die anschließende Immunpräzipitation mit Antihumanserum und monospezifischen Antiseren (Behring-Werke, Marburg) erfolgte bei $4^{\circ}$ in der Feuchtkammer innerhalb $48 \mathrm{Std}$. Danach wurden die Plättchen nativ photographiert.

Die Doppeldiffusion nach Ouchterlony (8) wurde auf Objektträgern durchgeführt. Agar und Puffer wie bei Immunelektrophorese. Diffusion und Präzipitation erfolgten bei $4^{\circ}$. Zur Dokumentation wurden die ungefärbten Plättchen im schräg einfallenden Durchlicht photographiert.

\section{Ergebnisse}

Nach Dialyse des Ausgangsserums gegen Wasser trat ein feinflockiger Niederschlag auf, der die wasserunlöslichen Euglobuline enthielt. Die immunelektrophoretische Analyse des Überstandes ergab keine wesentliche Änderung gegenüber dem Ausgangsmaterial (Abb. 1a). Nach weiterer Fällung des Überstandes mit Zinksulfat war der größte Teil der Serumproteine ausgefallen, insbesondere waren das $\gamma$ G-Globulin und die Hauptmenge des. Albumins gefällt worden. In Lösung blieben das $\gamma \mathrm{A}-\mathrm{Globulin}$, daneben geringe Mengen von Transferrin, einige weitere $\beta$ - und $\alpha$-Globuline und eine Spur Albumin. Dieser Überstand wurde mit Ammoniumsulfat versetzt. Das Präzipitat

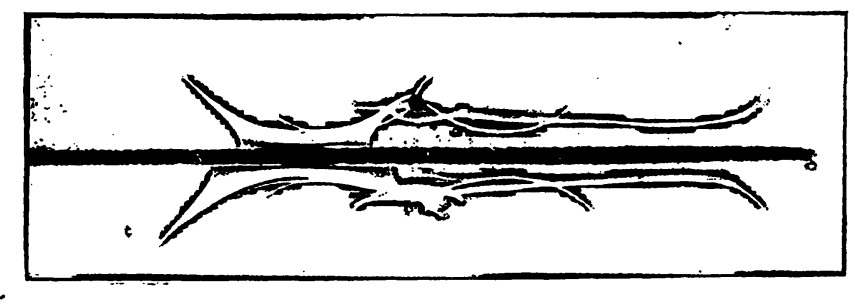
Abb. 1 a

Immunelektrophoretische Analyse des Oberstandes nach EuglobulinOben: Uberstand, unten: Ausgangsserum, Rinne: Antihumanserum 


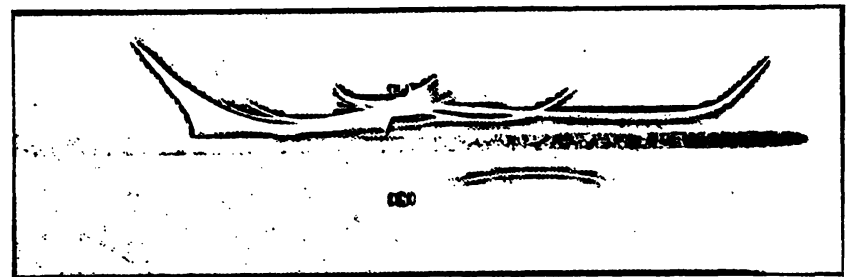

Abb. $1 \mathrm{~b}$

Immunelektrophorese des gelösten Präzipitates nach Ammoniumsulfatfällung (unten) im Vergleich zum Ausgangsserum (oben), entwickelt mit Antihumanserum

wurde in Säulenpuffer gelöst und immunelektrophoretisch untersucht (Abb. 1b).

Die weitere Fraktionierung dieses Proteingemisches durch Molekularsiebung an Sephadex G 200 ergab drei Fraktionen (Abb. 2), von denen die Fraktion II quantitativ stark überwog, während die Fraktion I und mehr noch die Fraktion III quantitativ seht klein war.

Die immunelektrophoretische Analyse der Fraktionen nach Gelfiltration zeigte in Fraktion I nur eine schwache Präzipitationsbande, die der $\gamma$ A-Globulinbande entsprach. Fraktion II enthielt reines $\gamma$ A-Globulin, das gleichzeitig gegenüber dem Ausgangsserum stark angereichert war. In Fraktion III fanden sich Transferrin,

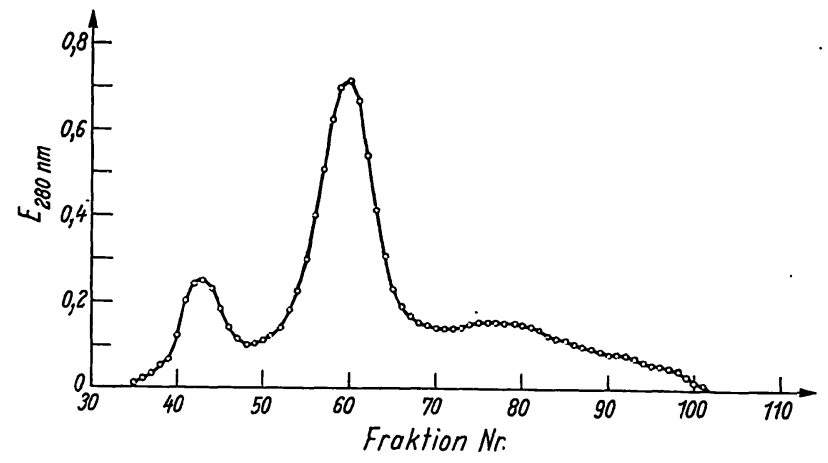

Abb. 2

Elutionsdiagramm nach Molekularsiebung des gelösten Präzipitates nach Ammoniumsulfatfällung

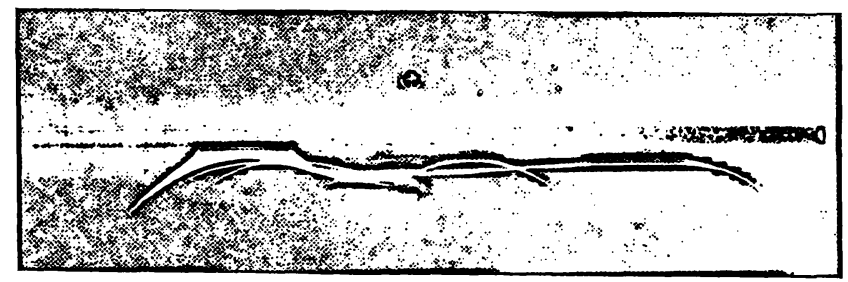

Abb. $3 a$

Immunelektrophoretische Analyse der Fraktion I nach Gelfiltration (oben) im Vergleich zum Ausgangsserum (unten) Fraktion I enthält reines $\gamma \mathrm{A}-\mathrm{Globulin}$ in geringer Menge

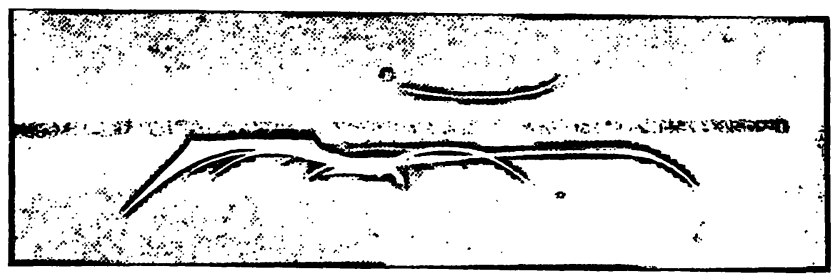

Abb. $3 b$

Immunelektrophorese der Fraktion II nach Gelfiltration (obè) im Vergleich zum Ausgangsserum (unten)

Die Fraktion enthält reines $\gamma \mathrm{A}-$ Globulin stark angereichert zwei Proteine mit $\beta$ - und $\alpha$-Beweglichkeit und etwas Albumin (Abb. 3a, b, c).

Der Nachweis der Identität der Fraktion II mit $\gamma \mathrm{A}$ Globulin wurde ferner durch Präzipitation mit monospezifischem Anti- $\gamma$ A-Globulinserum im Vergleich zum Normalserum erbracht (Abb. 3d). Eine Reaktion der Fraktion II mit monospezifischem Anti- $\gamma$ G-Globulinserum wurde dagegen nicht nachgewiesen (Abb. 3e), d. h. eine Verunreinigung des $\gamma$ A-Globulins in Fraktion II mit $\gamma$ G-Globulin wurde damit ausgeschlossen.

Entsprechend dem unterschiedlichen Elutionsvolumen bei der Gelfiltration wurden für die Fraktionen I und II, die immunelektrophoretisch beide $\gamma$ A-Globulin enthielten, unterschiedliche Sedimentationskonstanten ermittelt. Für Fraktion I wurde ein $\mathrm{S}_{\mathrm{c} 20}$-Wert von 12,6, für die Fraktion II ein $\mathrm{S}_{\mathrm{c} 20}$-Wert von 7,2 gefunden.

Ausgangsmaterial der Isolierung von $\gamma \mathrm{A}$-Globulinen waren Seren von Patienten mit biliärer Lebercirrhose, bei denen mit dem Antiglobulinkonsumptionstest und der Doppeldiffusionstechnik Antikörper gegen partikuläre Antigene aus Humanlebercytoplasma nachgewiesen worden waren. Nachdem die Prüfung der $\gamma G$ und $\gamma$ M-Globulinfraktionen dieser Seren keine Reaktion mit den betreffenden Antigenen ergeben hatte,

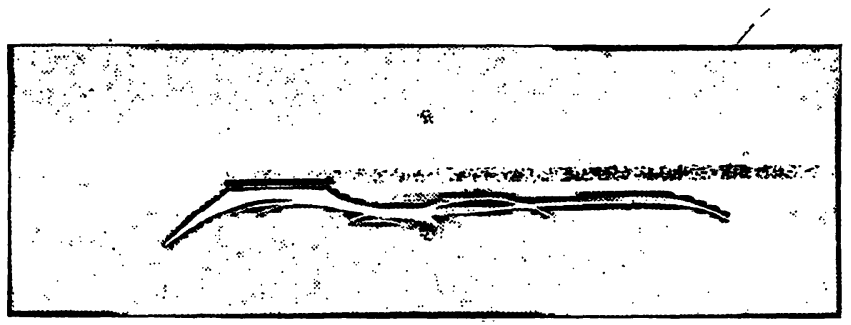

Abb. 3c

Immunelektrophorese der Fraktion III nach Gelfiltration (oben) im

Vergleich zum Ausgangsserum (unten) ält Transferrin, zwei Proteine mit
lichkeit und eine Spur Albumin

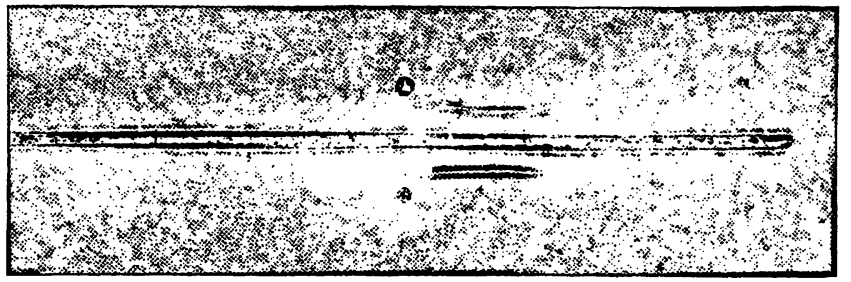

Abb. 3d

Immunelektrophorese der Fraktion II nach Gelfiltration (oben) im Vergleich zum Ausgangsserum (unten), entwickelt mit Anti- $\gamma$ A-

Die Präzipitationsbande entspricht der Bande in Abb. $3 \mathrm{~b}$ oben. Fraktion II ist demnach identisch mit $\gamma \mathrm{A}$-Globulin

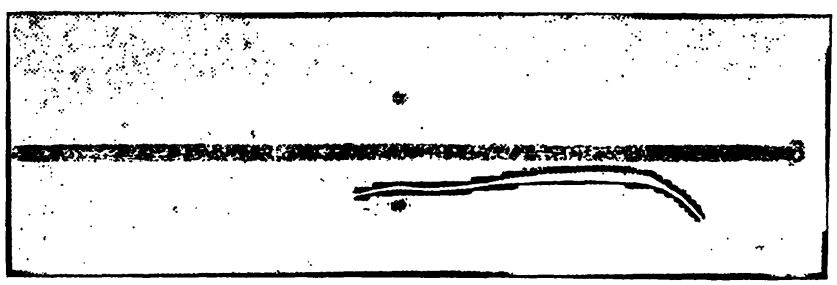

Abb. $3 \mathrm{e}$

Immunelektrophorese der Fraktion II nach Gelfiltration (oben) im Vergleich zum Ausgangsserum (unten), entwickelt mit Anti- $\gamma \mathrm{G}$ Globulinserum. Fraktion II ist frei von $\gamma \mathrm{G}-\mathrm{Globulin}$ 


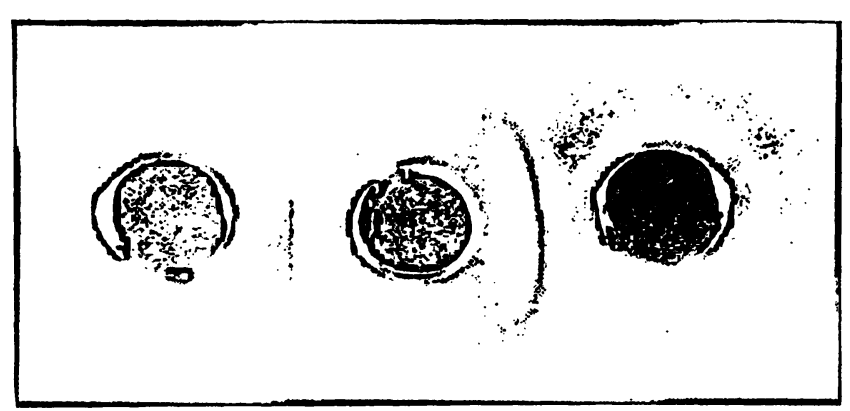

Abb. 4

Doppeldiffusionsansatz: Mitte: Humanleber-Mitochondrien, links: Ausgangsserum, rechts: Fraktion II nach Gelfiltration

Deutliche Reaktion des Ausgangsserums, sehr starke Reaktion des isolierten $\gamma \mathrm{A}$-Globulins mit Leber-Mitochondrien

wurden die nach der hier beschriebenen Methode durch Gelfiltration gewonnenen Fraktionen auf ihre Antikörperaktivität geprüft. Dabei ergab sich eine Reaktion der Fraktion II mit partikulären Leberzellantigenen (Mitochondrien) (Abb. 4), während Fraktion I und III inaktiv waren. Die Antikörperaktivität, die hier in der Fraktion der $\gamma$ A-Globuline lokalisiert war, hatte durch das. Trennverfahren keine Einbuße erfahren.

\section{Diskussion}

Durch die kombinierte Anwendung von Zinksulfatund Ammoniumsulfatfällung mit Gelfiltration ist eine Isolierung von IgA-Antikörpern aus Humanserum möglich. Diese Methode stellt eine vereinfachte Modifikation eines von VAERMAN und Mitarbeitern (2) sowie HeIDE und HAUPT (3) angegebenen Verfahrens dar. Auf die Zonenelektrophorese kann dabei ver- zichtet werden. Durch immunelektrophoretische Analyse der Fraktionen konnte der Nachweis der Identität und Reinheit der $\gamma \mathrm{A}$-Globulin-Präparation erbracht werden. Eine Beeinträchtigung der biologischen Aktivität von Antikörpern, die nach diesem Verfahren isoliert wurden, trat nicht ein, wie am Beispiel von Antikörpern gegen partikuläre Leberzellantigene gezeigt werden konnte.

Mit Hilfe dieser Methode wurde ein $\gamma \mathrm{A}$-Globulin mit der Sedimentationskonstante $7 \mathrm{~S}$ isoliert. Gleichzeitig fand sich in geringer Menge noch ein $\gamma \mathrm{A}-$ Globulin mit der Sedimentationskonstante $12,6 \mathrm{~S}$, das in der ersten Fraktion nach Gelfiltration ebenfalls rein eluiert wurde. $\mathrm{Ob}$ es sich bei dieser schweren Form des $\gamma \mathrm{A}$ Globulins um ein durch das Trennverfahren induziertes Aggregationsprodukt (8, 9), oder um die schwere Komponente des $\gamma$ A-Globulins (10) handelt, kann nicht entschieden werden. Eine Antikörperaktivität dieser schweren Komponente war nicht nachweisbar. Allerdings stand diese $13 \mathrm{~S}$-Fraktion nur in extrem kleiner Menge zur Verfügung. Eine ebenfalls von Herenrans (10) beschriebene 10,5 S-Komponente des $\gamma$ A-Globulins wurde nicht isoliert.

Zur Isolierung von $\gamma \mathrm{A}-\mathrm{Globulin}$ ist eine Kombination mehrerer Trennverfahren nicht zu umgehen. Die hier beschriebene Kombination von Fällungsreaktion und Gelfiltration führt in wenigen Trennschritten $z u$ einem immunologisch reinen Präparat. Diese Methode ist zur Isolierung von Antikörpern geeignet, denn eine Denaturierung der Proteine tritt bei exakter Durchführung nicht ein.

\section{Literatur}

1. Sober, H. A. und E. A. Peterson, Federation Proc. 17, 1116 (1958). - 2. Vaerman, J. P., J. F. Heremans und C. Vaerman, J. Immunol., Baltimore 91, 7 (1963). - 3. Herde, $K$. und $H$. Haupt, Behring-Werk Mitt. 43, 161 (1964). - 4. SchumaChER, K., diese Z. 4, 196 (1966). - 5. Schumacher, K., Klin. Wschr. 45, 1045 (1967). - 6. Flodin, P und J. KILLANDER, Biochim. biophysica Acta (Amsterdam) 63, 403 (1962). - 7. SCHEIDEGGER,
J. J., Internat. Arch. Allergy 7, 103 (1955). - 8. Ouchterlony, O., In: P. Kallos, Progress in Allergy. Basel and New York; S. Karger (1958). - 9. HeIDE, K., Bibl. Haemat. 12, 245 (1961). 10. IsLIKER, H. und E. F. LüsCHER, Helv. med. Acta 26, 152 (1959). - 11. Heremans, J. F., Bull. schweiz. Akad. med. Wiss. 17,119 (1961).
Priv.-Doz. Dr. K. Schumacher $5000 \mathrm{Köln}$-Lindenthal Josef-Stelzmann-Straße 9 